\title{
Dairy farmer attitudes and empathy toward animals are associated with animal welfare indicators
}

\author{
C. Kielland, ${ }^{* 1}$ E. Skjerve, $†$ O. Østerås, ${ }^{*}$ and A. J. Zanella* $\ddagger$ \\ *Department of Production Animal Clinical Sciences, Norwegian School of Veterinary Science, 0033 Oslo, Norway \\ †Department of Food Safety and Environment, Norwegian School of Veterinary Science, 0033 Oslo, Norway \\ $\ddagger$ Department of Animal and Aquacultural Sciences, Norwegian University of Life Sciences, 1432 Ås, Norway
}

\begin{abstract}
Attitudes and empathy of farmers influence humananimal interaction, thereby affecting their behavior toward animals. The goal was to investigate how measures of attitude and empathy toward animals were associated with animal welfare indicators such as milk yield, mastitis incidence, fertility index, and the prevalence of skin lesions on cows. To assess empathy toward animals, a photo-based pain assessment instrument was developed depicting various conditions that could be associated with some degree of pain in cattle and included questions aimed at assessing attitudes toward animals. Photos of painful conditions are useful in eliciting measurable empathic responses to pain in humans. A total of 221 farmers were sampled via e-mail and 154 responses were obtained. In the first analysis, farmers were categorized into 2 groups according to their agreement or disagreement with the attitude statement "animals experience physical pain as humans do." In the second analysis, farmers were assigned a median pain assessment score obtained from their estimates on the visual analog scale of 21 conditions assumed painful for cattle. In the third analysis, farmers were clustered in 3 groups according to their visual analog scale responses. Three conditions were ranked as the most painful: fracture of tuber coxae, dystocia, and serious mastitis. Farmers with positive attitudes toward animals scored 2 points higher on their empathy score compared with farmers with negative attitudes. Personal experience with each additional condition resulted in a 0.09 higher score. Cluster analysis revealed 3 groups. Farmers in group 3 had the highest median pain assessment score $(6.7 \pm 0.2)$, indicating a high level of empathy and a positive attitude toward animals. They had the lowest prevalence of skin lesions over the carpus $(24 \pm 6 \%)$ and the lowest milk production $(6,705 \pm 202 \mathrm{~kg})$. The complex associations between indicators of empathy and attitudes with relevant welfare outcomes suggest
\end{abstract}

Received November 11, 2009.

Accepted March 16, 2010.

${ }^{1}$ Corresponding author: camilla.kielland@nvh.no that competence building to safeguard animal welfare could benefit from including both attitudes and empathy in human-animal interactions studies.

Key words: dairy cattle welfare, empathy, attitude, milk production

\section{INTRODUCTION}

Farm animal welfare is dependent on human care. Farmers decide on both the choice in housing systems and how the system is managed. Inadequately designed and badly maintained facilities can cause skin lesions and reduced welfare. Previous research suggests a direct relationship between farmers' attitudes and behavior (Coleman et al., 1998; Breuer et al., 2000) and between farmers' behavior and their management decisions (Hemsworth, 2003). Their behavior affects dairy cattle management and the consequences of management decisions can be measured by defined variables related to production and health. Higher milk yield was reported in farms with positive indicators of human-animal interaction (HAI; Breuer et al., 2000; Hemsworth et al., 2000; Waiblinger et al., 2002). Hanna et al. (2009) reported that empathy was positively correlated with milk yield and that negative beliefs had a negative correlation with milk yield, and assessed negative beliefs using the response of farmers to statements such as "cows respond better to shouting than to a gentle voice." To our knowledge, no empirical data have been presented to link empathy with attitudes toward animals in pain with animal welfare. Animal welfare was assessed by including production measures (i.e., milk yield; Breuer et al., 2000), health outcomes (i.e., mastitis and fertility indexes; Barkema et al., 1999), and skin lesions (Huxley et al., 2004). Skin lesions are health indicators and can cause pain and discomfort to the animals (Rousing et al., 2000) and were a sign of dysfunctional housing design (Kielland et al., 2009a).

Two major approaches have previously been used to investigate empathy in humans. One approach used validated empathy tests (Elliott, 1982; Hojat et al., 2002; Hanna et al., 2009). Another approach relied on 
the observed responses of subjects to pictures of individuals in various situations that could be associated with pain (Jackson et al., 2005, 2006; Singer, 2006). Empathy tests should be specially designed to attend the particular characteristics of the population that is to be assessed (Hojat et al., 2002). Reports of this approach to farmers have not been published. To measure empathy of dairy farmers to cows, a novel approach was tested in veterinary students using pictures of cattle in situations assumed painful (Kielland et al., 2009b).

When shown to human subjects, pictures and films of painful conditions were believed to elicit empathic responses, recorded as activation of similar brain pathways as if the subject experienced the pain himself or herself (Jackson et al., 2005). The rationale to extend human empathy studies to animals is that pain perception is an important biological mechanism that evolved to protect the individual against damage and injury. An evolution-based compelling argument is that pain is a phylogenetically widespread experience found in all vertebrates and probably some invertebrates (Bateson, 1991).

It is proposed that parallels can be drawn between empathy toward fellow humans and toward animals. Furthermore, cross-species empathy likely occurs in the context of HAI. This concept was validated by investigating empathy of dog owners toward their dog. Ellingsen et al. (2010) found a high agreement between their pain assessment instrument (PAI) and earlier validated empathy and attitude instruments (Templer et al., 1981; Paul, 2000), indicating that cross-species empathy was a likely occurrence. Some of the factors that can influence a person's empathy are their family relatedness, age, sex, previous experience, and the quality of the association between the test subject and the person experiencing pain (Carlozzi et al., 1983; Allott, 1992). Previously, attitudes of veterinarians (Huxley and Whay, 2006; Hewson et al., 2007) and veterinary students (Kielland et al., 2009b) toward animals in pain were assessed. In the previous studies mentioned above, combined measures of empathy and attitudes are seldom present.

Our aims were to investigate attitudes and empathy of farmers toward animals in pain using a picture-based PAI to study potential links between farmers' attitudes with empathy, and to study how animal welfare indicators such as mastitis, fertility index, milk production, and skin lesions were associated with attitudes and empathy of farmers.

\section{MATERIALS AND METHODS}

A questionnaire was completed in March 2007 and e-mailed to 221 free stall farms that participated in an epidemiological study called "Free stalls for dairy cattle" in Norway, Kubygg (www.kubygg.no). The overall aim of the Kubygg study was to investigate how building design and management influenced animal welfare in Norwegian free stall dairy herds. Population sampling was performed as described previously (Kielland et al., 2009a). In Norway, Norwegian Red cattle are the predominant breed, and all 221 farms had Norwegian Red on their farms, ranging from 89 to $100 \%$ of the animals.

The questionnaire including the PAI was designed by C. Kielland using an online survey program (Questback, Oslo, Norway). The PAI was described, validated, refined, and pilot tested with veterinary students as responders (Kielland et al., 2009b). In the present paper, in contrast to the PAI used previously (Kielland et al., $2009 \mathrm{~b}$ ), all the conditions were supplemented with pictures of a condition assumed painful for cattle. These conditions were called painful conditions in the following text, even if they were not tested in the present paper. In addition, questions on attitudes were included and additional demographic data were collected.

The 221 farmers who received the PAI questionnaire via electronic mail were asked to assess the pain level of 21 different conditions, indicating their answer on a visual analog scale (VAS). The respondents were asked whether they were in charge of the management of the animals and, if not, who was in charge. Displayed in the questionnaire was the name of the condition (e.g., severe mastitis) followed by a picture of a cow with the specific condition (Figure 1). Underneath the picture, a 10-cm VAS was available for farmers to score their assessment of the pain associated with the condition, marking on a blue line with a scale from 0 to $10(0=$ no pain, $10=$ unbearable pain; Figure 1). Participants had to click on the blue line and the information would automatically register on a server. The questions were standardized by not including detailed information about the various diseases. This method was used to capture the immediate response to the picture and not focus on details about the diseases and conditions.

Demographic data collected from the farmers included their age, sex, experience with cattle (years), and education (elementary school, lower degree, higher degree). In addition, farmers were asked whether they had conventional or organic farms, the number of farmers in cooperative operations, and whether the farmer had a personal experience with the diseases presented in the questionnaire. These demographic factors were used in the analyses and mentioned as predictor variables even if some of the variables proved to be confounding factors and not only predictor variables.

To investigate how health, production, and welfare indicators at farm level may be related to farmers' 


\section{Significant differences in group $3(\Delta)$, compared to $1(\diamond)$ and $2(\square)$ : High median pain assessment score (mPAS) Older farmers Better reproduction status Lower prevalence of skin lesions on front knee}

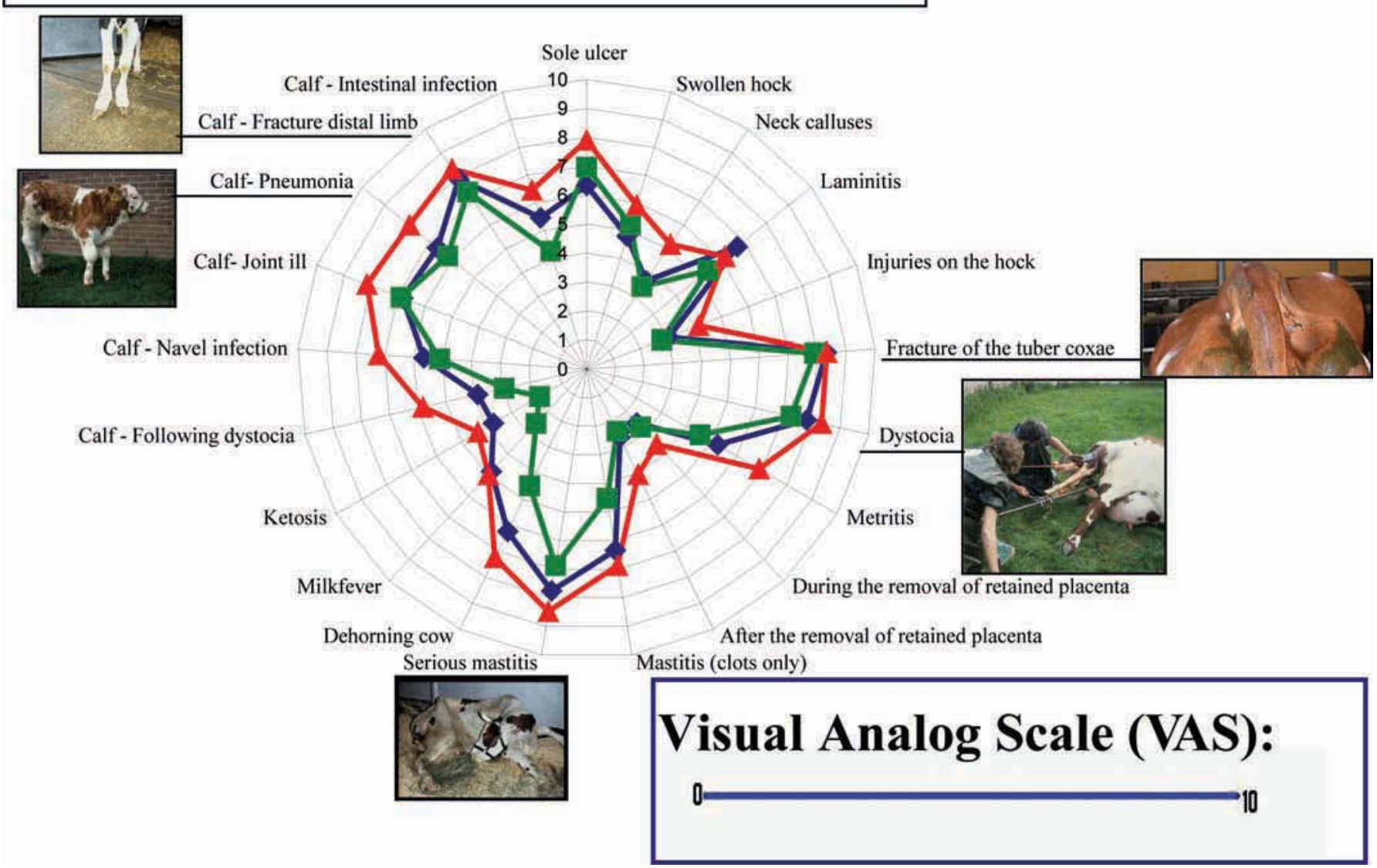

Figure 1. Farmers were clustered into 3 groups according to their overall continuous visual analog scale response pattern, which was obtained on a $10-\mathrm{cm}$ blue line: 0 was recorded as no pain and 10 was recorded as unbearable pain. A spider web was used to visualize how the 3 groups varied on a median pain assessment score. Group 1 is the diamonds, group 2 is the squares, and group 3 is the triangles. Additionally, differences in possible demographic-related factors and some cow health-related variables were tested across the 3 groups. Group 3 differed from the other 2 groups according to skin lesions $(P<0.03)$ and milk production $(P<0.04)$, and tended to be different according to farmers' age $(P<0.09)$ and cows reproduction performance $(P<0.07)$. Photos shown are the 5 scored as most painful conditions from the questionnaire. Color version available in the online PDF.

attitudes and different measures of empathy toward animals, the questionnaire data were merged with data from the Norwegian Dairy Herd Recording System database (Ås, Norway) as herd level data from the year 2006. Detailed data on health, production, and welfare indicators for each herd regarding milk production, herd size, mastitis incidence, and farm fertility index were collected from that database. These data were recorded each time a veterinarian treated an animal. Only veterinarians are allowed to administer drugs to cattle in Norway, making the health recordings very informative (Østerås et al., 2007).
From the project called "Free stalls for dairy cattle," data on the herd prevalence of skin lesions were added to this data set. The method of recording herd prevalence of skin lesions was described elsewhere (Kielland et al., 2009a).

\section{Analytical Approach}

Data from each of the responders were stored in a database on a web server (www.Questback.no). After completing the study, data were exported to Excel 
(Microsoft Corp., Redmond, WA), where initial data processing and quality checking were undertaken.

Primary data analysis was conducted using profile plots in Excel, where median scores of the various conditions were plotted against the various predictors. For further statistical and graphical analysis, data were transferred to Stata (Stata SE/10 for Windows, Stata Corp., College Station, TX). Statistical significance level was set to $P \leq 0.05$. A $P$-value between 0.05 and 0.10 was interpreted as a tendency of association, and $P$-values higher than 0.10 were interpreted as nonsignificant associations.

In addition to age, sex, and experience of the farmer, animal welfare indicators were entered as predictor variables in the 3 different parts (A, B, and $\mathrm{C}$ ). Indicators tested included herd prevalence of skin lesions on tarsus (hock), prevalence of skin lesions over the carpus (knee), yearly mastitis incidence per farm, yearly fertility index per farm, and yearly milk production per cow. Farm fertility index in Norwegian dairy farms was calculated as a number that gave an overview of how well the reproduction was managed at the farm. The index ranged from 0 to 120 and was calculated as follows:

$$
\text { Fertility index }=\frac{[a / b-(c-125)] \times(e-d)}{e},
$$

where $a=$ nonreturn after $60 \mathrm{~d}(\%)+$ percentage of 2 or 3 inseminations in same estrus; $b=$ number of services per inseminated cow or heifer; $c=$ average number of days between calving and last AI; $d=$ number of cows culled because of infertility; and $e=$ total number of inseminated cows or heifers

In Part A, a dichotomous outcome was used, reflecting farmers' attitudes toward animals with the goal of comparing negative versus positive beliefs toward animals. The respondent would indicate on a 5-point Likert scale whether he or she agreed or disagreed with the statement "animals experience physical pain as humans do." Logistic regression was performed with a dichotomous outcome designed by assigning those who agreed into one group (1) and those who disagreed into another group (0). Hemsworth et al. (2002) categorized "dairy cows don't feel pain" as a negative attitude.

Part B used the median pain score (scored on the VAS) of each farmer, called the median pain assessment score (mPAS), as an outcome. Associations between attitude and mPAS outcome were tested in a linear regression model. The predictor variables were entered in a forward stepwise method after visually exploring the relationship between the outcome and predictor. For the visualization of the relationship between the continuous outcome (mPAS) and the dichotomous attitude predictor, a logit function in Stata was used through the lowess command.

In Part C, cluster analysis in Stata based on a complete linkage with standard Euclidian measure was used. This program assigned the farmers to groups according to the individual response on the VAS for each painful condition $(\mathrm{n}=21$ conditions $)$. Each farmer with a similar response ended up in one group, and those with a different way of responding ended up in another group. The computer started with 2 groups, then 3 , then 4 , and so on. The number of acceptable groups was dependent on the robustness of the data. The robustness was tested after each additional group was created. When the model was deemed unstable (visible by unstable group size), the previous number of groups was used. All painful conditions were weighted equally. Cluster analysis preserved the individual response pattern for each farmer and the results from the cluster analysis were presented as a dendrogram (Figure 2). The defined groups were tested against the animal welfare outcomes using the Kruskal-Wallis test.

\section{RESULTS}

The response rate was $70 \%(\mathrm{n}=154)$. Five responders were removed from the analyses because of their lack of response to 19 or more of the 21 questions about painful conditions. Of the 149 responses used in the analysis, $13 \%$ were females $(\mathrm{n}=19)$ and $87 \%$ were males $(\mathrm{n}=$ 130). The age of the study population ranged from 26 to $68 \mathrm{yr}$, and experience with cattle varied from 6 to 58 yr. Most of the farmers $(69 \%)$ had at least a high school education. Mean herd size per year was 37 animals (SE \pm 1.3 ), ranging from 18 to 82 . Mean milk production was $7,139 \pm 73 \mathrm{~kg} / \mathrm{yr}$, with a range from 4,981 to $9,249 \mathrm{~kg}$. The farm fertility index ranged from 37 to 145, with a mean of $79 \pm 1.5$. Organic farmers represented $8 \%$ of the sample population. Of the respondents, $94 \%$ were the main caretakers of the animals. Table 1 summarizes the demographic measures in the sample population.

The mPAS of the 21 painful conditions are given in Table 2. The mean value of the total mPAS was $5.3 \pm$ 1.3 , with a range from 1 to 10 . Tuber coxae fracture, dystocia, and serious mastitis were ranked the most painful conditions in adult cattle. For calves, the 3 most painful conditions were fracture of lower limb, joint ill (lame and swollen joint due to arthritis), and pneumonia.

\section{Part A: Categorizing Farmers into 2 Groups}

The majority of farmers either agreed (39\%) or totally agreed $(31 \%)$ with the statement that animals experience physical pain as humans do. However, $13 \%$ of 


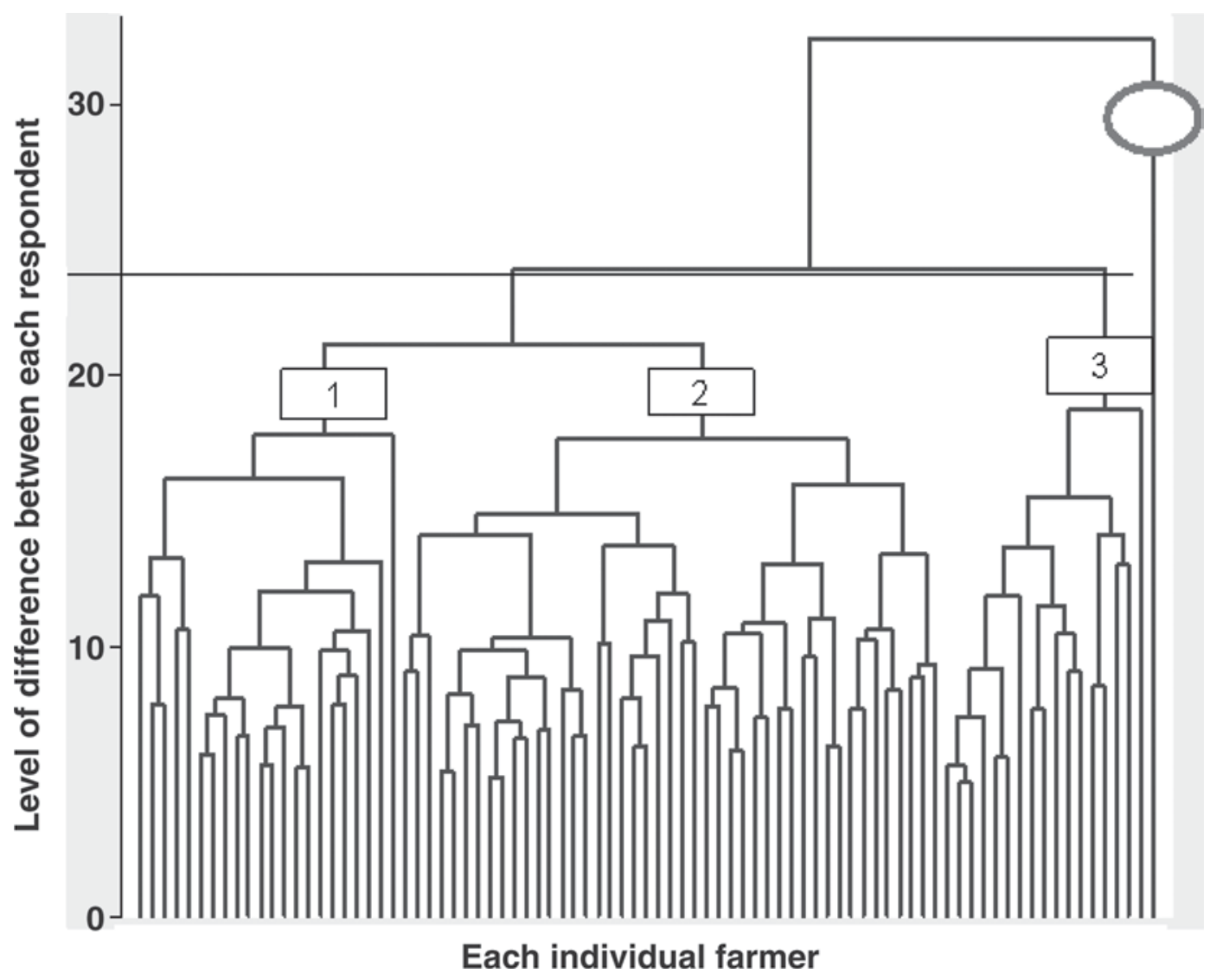

Figure 2. Results from the cluster analysis using the complete linkage application in Stata (Stata SE/10 for Windows, Stata Corp., College Station, TX). Three main groups were indentified. Each vertical line represents each response from each individual farmer who responded on the questionnaire on the 10-cm visual analog scale ranging from 0 , recorded as no pain, to 10, recorded as unbearable pain. Farmers were shown photos of 21 painful conditions. The vertical line to the right identifies 1 farmer as an outlier (circled).

farmers disagreed, $2 \%$ totally disagreed, $13 \%$ were indifferent, and $2 \%$ did not answer the statement. Graphical evaluation of the milk production and the dichotomous attitude statement showed that the relationship was not linear, and quartiles of milk production were made. The odds that the farmer would agree versus disagree with the pain statement increased when 1) the farmer had a higher mPAS $(\mathrm{OR}=1.6), 2)$ the farmer had a lower herd prevalence of skin lesions over the carpus (OR = 0.98 ), and 3 ) the herd milk production level ranged between 7,097 and $7,813 \mathrm{~kg}(\mathrm{OR}=10.3)$ compared with herds that produced between 4,981 and 6,527 kg (Table $3)$. No associations were identified with the statement "animals experience physical pain as humans do" and the following demographic measures: sex, education, number of owners, type of farming, and the number of years working with cattle. Clinical mastitis incidence showed no association with the pain statement cited above $(P=0.887)$.

\section{Part B: Using the Median Score for Each Farmer as an Outcome}

Age, sex, education, number of owners in a single farm, type of farming, mastitis incidence, and the number of years working with cattle were not associated with the mPAS. Another indicator of experience was obtained by asking how many of the conditions the farmer had previous personal experience with. For each of the 21 conditions they had personally experienced at their farm, they scored 0.09 points higher on the mPAS $(P=0.03)$.

When the attitude variable (from part A) was entered as a fixed effect into the linear regression model, the mPAS decreased by 2 points when comparing those who disagreed with those who agreed $(P>0.01)$.

Farmers who managed units with the highest milk production per cow year (range: 7,813-9,249 kg) had a tendency of 0.52 lower mPAS scores $(P=0.08)$ than 
Table 1. Summary of the distribution of the demographic measures collected from the participating farmers $(\mathrm{n}=149)$

\begin{tabular}{lrr}
\hline Demographics and categories & $\mathrm{n}(\%)$ & Mean (range) \\
\hline Age, yr & & $46.0(26-68)$ \\
Sex & $130(87)$ & \\
Male & $19(13)$ & \\
Female & & \\
Experience, ${ }^{1}$ yr & $5(6-58)$ \\
Education & $102(69)$ & \\
Elementary school & $22(15)$ & \\
High school & $17(11)$ & \\
High school specialization & $3(2)$ & \\
Higher (university) degree & & \\
Missing information & $98(66)$ & \\
Farming style & $12(8)$ & \\
Conventional & $39(26)$ & $37(18-82)$ \\
Organic & $36(24)$ & \\
Missing information & $95(64)$ & \\
Owners, ${ }^{2}$ n & $17(12)$ & \\
One owner & & \\
Joint company (more than one owner) & & \\
Missing information & & \\
Animals/yr per farm, ${ }^{3} \mathrm{n}$ & & \\
Milk production/cow year, ${ }^{3}$ kg &
\end{tabular}

${ }^{1}$ Working experience with cattle.

${ }^{2}$ Several herds have multiple owners.

${ }^{3}$ Herd level data from the year 2006 from the Norwegian Dairy Herd Recording System (Ås, Norway).

those who had the lowest milk production $(4,981-6,527$ $\mathrm{kg}$; Table 4).

\section{Part C: Integrative Pattern of Individual Response Using Cluster Analysis}

According to the overall response pattern, cluster analysis using complete linkage revealed 3 distinct groups (Figure 2). Figure 1 displays how the 3 groups were distributed according to mPAS, using a spider web graph. Farmers in group 3 scored highest on almost all 21 painful conditions. The VAS is visible in Figure 2. The mPAS was 5.8, 4.9, and 6.7 in groups 1,2 and 3, respectively. Farmers who were clustered in group 3 had the highest mean mPAS $(P=0.001)$, the lowest prevalence of skin lesions over the carpus $(P=0.03)$, and the lowest milk production $(P=0.04$; Figure 3$)$. The data indicated that farmers in group 3 tended to be older (48 $\pm 1.7 \mathrm{yr} ; P=0.09)$ compared with groups 1 and 2 , with a mean age of 43 and $45 \mathrm{yr}$, respectively. They tended to have had the highest farm fertility index $(87 \pm 3)$ compared with the other groups $(P=$ $0.07)$, both with a mean of 77 .

\section{DISCUSSION}

When assessing farmers' attitudes, indicators of negative beliefs, reflected by the disagreement with the statement "animals experience physical pain as humans do," were associated with higher prevalence of skin lesions over the carpus (Table 3), possibly supporting the relationship between farmers' attitudes, management, and care of their animals. It is possible that this relationship could be coincidental, but similar findings using the same data set were reported when animals were used as observational units (Kielland et al., 2009a). Different management styles were associated with attitudes and with bulk milk SCC (Barkema et al., 1999). Coleman et al. (1998) and Breuer et al. (2000) found that attitudes were correlated with farmers' behavior.

The mPAS preserved some of the complexity of the personality traits relevant to empathy and it is proposed that the responses on the mPAS were a measure of farmers' empathy toward animals. As mentioned earlier, this argument was supported by a recent study that used an instrument similar to PAI, tailored for dog owners, which had a high agreement with validated empathy and attitude instruments (Ellingsen et al., 2010). Interestingly, there was agreement between the mPAS given by farmers in the present study with Norwegian veterinary students (Kielland et al., 2009b) and with veterinarians in the United Kingdom (Huxley and Whay, 2006), comparing median score given for the same conditions.

Females did not score significantly higher in attitudes and empathy measures reported in this study, in contrast to previous studies (Capner et al., 1999; Kielland et al., 2009b; Lascelles et al., 1999). One possible reason 
for this difference is that only $13 \%$ of the responders were females.

Characteristics identified as typical for group 3 farmers were a low occurrence of skin lesions over the carpus and low milk production compared with groups 1 and 2. This group was identified using cluster techniques and dendrograms. Cluster techniques proved very informative for preserving the finer details within each individual response when students were grouped according to their empathy score (Kielland et al., 2009b). The focus of the instrument used in the current study was on responses of farmers to painful conditions in dairy cattle, in contrast to previous studies that used responses to an array of questions to conduct factor analysis or principal component analysis (Hemsworth et al., 2000; Waiblinger et al., 2002; Hanna et al., 2009). Pain assessment was selected as a defined topic that was closely related to empathy (Jackson et al., 2005). Interpretation of the findings of the current study was less likely affected by confounders inherently present with self reports on a broad array of questions as used in other studies (Waiblinger et al., 2002; Hanna et al., 2009).

A relationship was identified between positive attitudes, measured in response to the statement "animals experience physical pain as humans do," and a high mPAS linking an indicator of attitudes with measures of empathy. One single question may not suffice to characterize the attitudes of dairy farmers. However, these results support previous findings indicating that questions related to negative beliefs about animal pain

Table 2. Median pain assessment score and range of the estimated severity of pain associated with 21 different conditions (illustrated with a picture) in adult cattle and calves, scored by 149 dairy farmers using a visual analog scale

\begin{tabular}{|c|c|c|}
\hline Condition & Median pain assessment score & Range \\
\hline \multicolumn{3}{|l|}{ Cattle } \\
\hline Fracture of Tuber coxae (one sided) ${ }^{1}$ & 8.6 & $0-10$ \\
\hline Dystocia $^{2}$ & 7.6 & $1-10$ \\
\hline Serious mastitis ${ }^{3}$ & 7.6 & $0-10$ \\
\hline Sole ulcer & 7.1 & $0-10$ \\
\hline Eye infection ${ }^{4}$ & 5.7 & $0-10$ \\
\hline Laminitis $^{5}$ & 5.7 & $1-10$ \\
\hline Mastitis (clots only) ${ }^{6}$ & 5.7 & $0-10$ \\
\hline Swollen hock & 5.2 & $1-10$ \\
\hline Dehorning cow & 5.2 & $0-10$ \\
\hline Acute metritis ${ }^{7}$ & 4.8 & $0-10$ \\
\hline Neck calluses & 3.3 & $0-10$ \\
\hline Milk fever ${ }^{8}$ & 3.3 & $0-9$ \\
\hline Skin lesions on hock (tarsus) & 2.9 & $0-9$ \\
\hline Removal of retained fetal membranes ${ }^{9}$ & 2.4 & $0-7$ \\
\hline After the removal of the placenta & 2.4 & $0-7$ \\
\hline \multicolumn{3}{|l|}{ Calves } \\
\hline Distal limb fracture ${ }^{10}$ & 7.6 & $0-10$ \\
\hline Joint ill ${ }^{11}$ & 6.7 & $1-10$ \\
\hline Pneumonia $^{12}$ & 6.7 & $2-10$ \\
\hline Navel infection ${ }^{13}$ & 5.2 & $1-10$ \\
\hline Intestinal infection ${ }^{14}$ & 4.8 & $1-10$ \\
\hline Following dystocia $^{15}$ & 3.3 & $0-9$ \\
\hline
\end{tabular}

${ }^{1}$ Picture taken from behind the cow, in which the left coxal tuber is visibly lower than the right.

${ }^{2}$ Picture of 2 people assisting with a cow calving.

${ }^{3}$ Picture of a cow severely affected by an udder infection. The cow is lying in lateral decumbency. No close up of an udder was visible in that picture.

${ }^{4}$ Close up picture of the right eye of a cow suffering from uveitis.

${ }^{5}$ Picture of a cow standing with the 2 front legs crossed.

${ }^{6}$ Picture of an udder with typical signs of a local inflammation: calor, dolor, rubor, and tumor (heat, pain, redness, and swelling).

${ }^{7}$ Picture taken from behind a cow $2 \mathrm{~d}$ after calving; discharge is visible around the tail.

${ }^{8}$ Cow lying down in lateral decumbency.

${ }^{9}$ Picture of a person taking the temperature of a cow when the placenta is hanging from the vulva.

${ }^{10}$ Frontal picture of a calf where the angle of the left front leg indicates a fracture is present (diagnosed as a fracture of one of the phalanx bones).

${ }^{11}$ Lateral picture of a calf with a swollen carpus (diagnosed as joint infection of the carpus).

${ }^{12}$ Picture of a calf with nasal and ocular discharge.

${ }^{13}$ Close up picture of a swollen navel with visible purulent discharge.

${ }^{14}$ Picture of a calf defecating watery feces.

${ }^{15}$ Picture of a calf being extracted from its dam. 
Table 3. Results from a logistic regression from 127 dairy farmers who agreed with the statement "animals experience physical pain as humans do" (1) and those who disagreed with that statement $(0)^{1}$

\begin{tabular}{|c|c|c|c|c|c|c|}
\hline \multirow[b]{2}{*}{ Fixed effect and class } & \multirow[b]{2}{*}{ Estimate $(\beta)$} & \multirow[b]{2}{*}{$\mathrm{SE}$} & \multirow[b]{2}{*}{$\mathrm{OR}^{2}$} & \multicolumn{2}{|c|}{$95 \% \mathrm{CI}^{3}$} & \multirow[b]{2}{*}{$P$-value } \\
\hline & & & & Lower & Upper & \\
\hline \multicolumn{7}{|c|}{ Median pain assessment score ${ }^{4}$} \\
\hline Continuous & 0.45 & 0.19 & 1.57 & 1.08 & 2.28 & 0.018 \\
\hline \multicolumn{7}{|c|}{ Skin lesions over the carpus (herd prevalence) $)^{5}$} \\
\hline Continuous & -0.02 & 0.01 & 0.98 & 0.96 & 0.99 & 0.042 \\
\hline \multicolumn{7}{|c|}{ Milk production (quartiles), ${ }^{6} \mathrm{~kg}$} \\
\hline $4,981-6,527$ & 0 & - & 1 & - & - & - \\
\hline $6,538-7,913$ & 0.19 & 0.67 & 1.20 & 0.33 & 4.43 & 0.779 \\
\hline $7,097-7,813$ & 2.33 & 1.13 & 10.3 & 1.13 & 94.3 & 0.039 \\
\hline $7,813-9,249$ & -0.38 & 0.17 & 1.18 & 0.35 & 4.09 & 0.782 \\
\hline
\end{tabular}

${ }^{1}$ The original 5 -point Likert scale was transformed into a dichotomous variable.

${ }^{2}$ Odds ratios.

${ }^{3} 95 \%$ CI, lower and upper limits, of the OR.

${ }^{4}$ Median pain score for each farmer that scored all the 21 conditions assumed to be painful for cattle on a visual analog scale from 0 (no pain) to 10 (unbearable pain).

${ }^{5}$ Herd prevalence of any signs of changes of the skin over the carpus (knee) ranging from hair loss, swelling, and wounds. Data collected from another study but with the same sample of farmers (Kielland et al., 2009a).

${ }^{6}$ Milk yield per cow year. Data collected in 2006 from the database of the Norwegian Dairy Herd Recording System (Ås, Norway).

were correlated with 2 of 5 known and validated human personalities, agreeableness and conscientiousness (Hanna et al., 2009). These findings provide foundation to support that the attitude measure of dairy farmers used in the current study is an acceptable way to group human personalities.

The results from the current study identified associations between measures of animal welfare at farm level and farmer's attitudes and empathy toward animals. Yet, these results can give only indications on the strengths of association between predictors and outcomes. Furthermore, no inferences on causality can, or should, be drawn from this work. Therefore, interpre- tations should be made with caution because of the novelty of the methodology explored in this study that included HAI, animal welfare, health, and production measures. Altogether, farmers who want to improve and safeguard animal welfare could benefit by changing and improving how animals are handled.

\section{ACKNOWLEDGMENTS}

The authors thank the participating farmers and technicians Hans Kristian Hansen and Stine Kvivesen (The North Trønderlag University College, Steinkjer, Norway) for their help and support during the trial.

Table 4. Estimates from linear regression analysis with the median pain assessment score as an outcome ${ }^{1}$

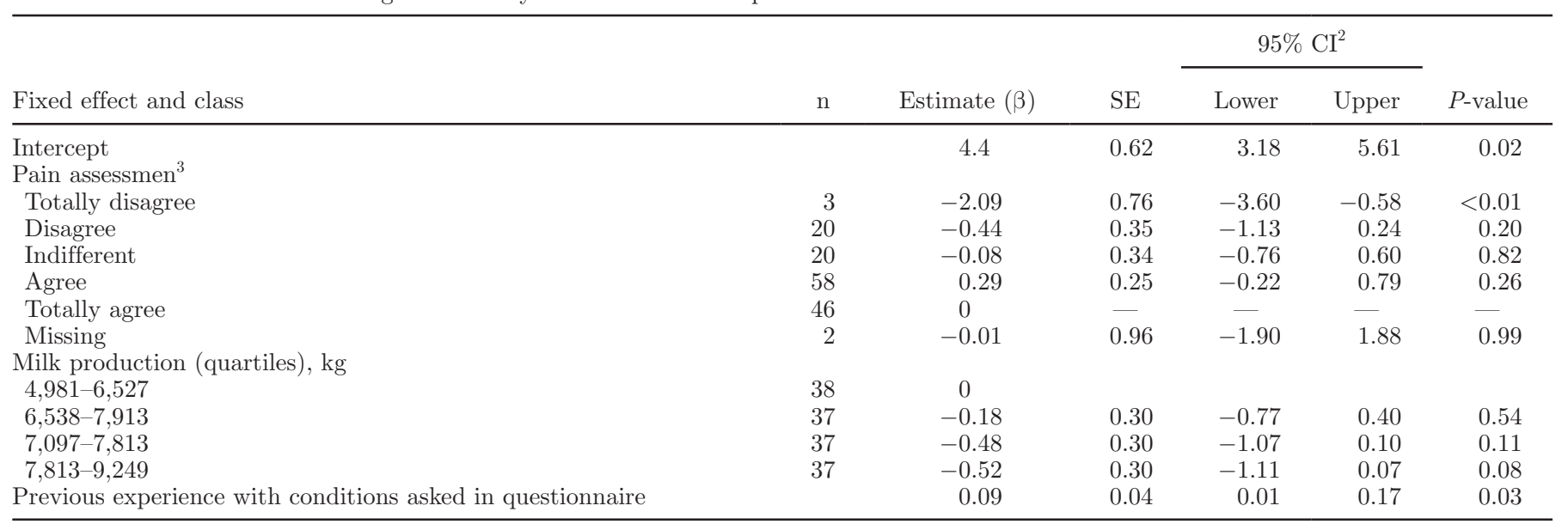

${ }^{1}$ The median pain assessment score was designed for each of the 149 farmers who scored all the 21 assumed painful conditions for cattle on a visual analog scale ranging from 0 (no pain) to 10 (unbearable pain).

${ }^{2}$ Confidence interval, lower and upper limits.

${ }^{3}$ Farmers' assessment of the statement "animals feel physical pain as humans do" on a 5-point scale, from totally disagree to totally agree. 


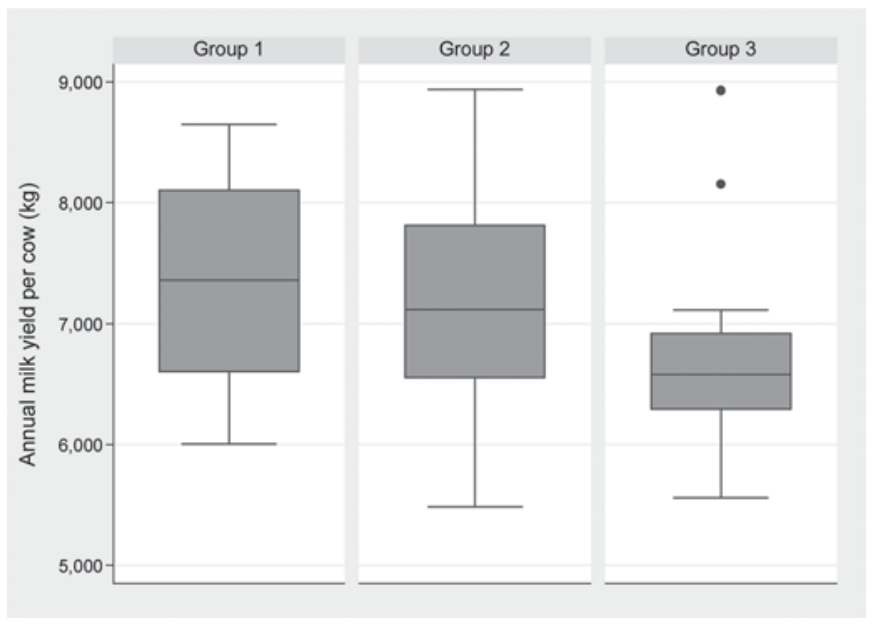

Figure 3. Distribution of milk production among the 3 groups of farmers identified in the cluster analysis considering the overal response pattern to the pain assessment scores in the 21 painful conditions included in the photo-based pain assessment instrument.

The access to the data was given by the Norwegian Dairy Herd Recording System (NDHRS) and the Norwegian Cattle Health Services (NCHS, Âs, Norway; for health data) in agreement number $3 / 2006$. The study was financially supported by grants from the Research Council of Norway (Oslo; 15\%), Agricultural Agreement Research Fund (Oslo, Norway; 16\%), and Foundation for Research Levy on Agricultural Products (Oslo, Norway; $69 \%$ ). Peter Jackson (University of Cambridge, Cambridge, UK) provided some of the pictures used in the instrument. The authors acknowledge the assistance of Camie R. Heleski (Department of Animal Science, Michigan State University, East Lansing). Ken Leslie (Department of Population Medicine, University of Guelph, Guelph, Ontario, Canada) kindly helped to improve the English of the manuscript.

\section{REFERENCES}

Allott, R. 1992. Evolutionary aspects of love and empathy. J. Soc. Evol. Syst. 15:353-370.

Barkema, H. W., J. D. V. Ploeg, Y. H. Schukken, T. J. G. M. Lam, G. Benedictus, and A. Brand. 1999. Management style and its association with bulk milk somatic cell count and incidence rate of clinical mastitis. J. Dairy Sci. 82:1655-1663.

Bateson, P. 1991. Assessment of pain in animals. Anim. Behav. 42:827-839.

Breuer, K., P. H. Hemsworth, J. L. Barnett, L. R. Matthews, and G. J. Coleman. 2000. Behavioural response to humans and the productivity of commercial dairy cows. Appl. Anim. Behav. Sci. 66:273-288.

Capner, C. A., B. D. X. Lascelles, and A. E. Waterman-Pearson. 1999 Current British veterinary attitudes to perioperative analgesia for dogs. Vet. Rec. 145:95-99.

Carlozzi, A. F., J. P. Gaa, and D. B. Liberman. 1983. Empathy and ego development. J. Couns. Psychol. 30:113-116.

Coleman, G. J., P. H. Hemsworth, and M. Hay. 1998. Predicting stockperson behaviour towards pigs from attitudinal and job- related variables and empathy. Appl. Anim. Behav. Sci. 58:6375 .

Ellingsen, K., A. J. Zanella, E. Bjerkås, and A. Indrebø. 2010. Studying the relationship between empathy, perception of pain and attitudes toward pets among Norwegian dog owners. Anthrozoos 23. (In press.)

Elliott, R. 1982. Measuring response empathy: The development of a multicomponent rating scale. J. Couns. Psychol. 29:379-387.

Hanna, D., I. A. Sneddon, and V. E. Beattie. 2009. The relationship between the stockperson's personality and attitudes and the productivity of dairy cows. Animal 3:737-743.

Hemsworth, P. H. 2003. Human-animal interactions in livestock production. Appl. Anim. Behav. Sci. 81:185-198.

Hemsworth, P. H., G. J. Coleman, J. L. Barnett, and S. Borg. 2000 Relationships between human-animal interactions and productivity of commercial dairy cows. J. Anim. Sci. 78:2821-2831.

Hemsworth, P. H., G. J. Coleman, J. L. Barnett, S. Borg, and S. Dowling. 2002. The effects of cognitive behavioral intervention on the attitude and behavior of stockpersons and the behavior and productivity of commercial dairy cows. J. Anim. Sci. 80:68-78.

Hewson, C. J., I. R. Dohoo, K. A. Lemke, and H. W. Barkema. 2007. Canadian veterinarians' use of analgesics in cattle, pigs, and horses in 2004 and 2005. Can. Vet. J. 48:155-164.

Hojat, M., J. S. Gonnella, T. J. Nasca, S. Mangione, M. Vergare, and M. Magee. 2002. Physician empathy: Definition, components, measurement, and relationship to gender and specialty. Am. J. Psychiatry 159:1563-1569.

Huxley, J. N., J. Burke, S. Roderick, D. C. J. Main, and H. R. Whay. 2004. Animal welfare assessment benchmarking as a tool for health and welfare planning in organic dairy herds. Vet. Rec. 155:237239.

Huxley, J. N., and H. R. Whay. 2006. Current attitudes of cattle practitioners to pain and the use of analgesics in cattle. Vet. Rec 159:662-668.

Jackson, P. L., A. N. Meltzoff, and J. Decety. 2005. How do we perceive the pain of others? A window into the neural processes involved in empathy. Neuroimage 24:771-779.

Jackson, P. L., P. Rainville, and J. Decety. 2006. To what extent do we share the pain of others? Insight from the neural bases of pain empathy. Pain 125:5-9.

Kielland, C., L. E. Ruud, A. J. Zanella, and O. Østeras. 2009a Prevalence and risk factors for skin lesions on legs of dairy cattle housed in freestalls in Norway. J. Dairy Sci. 92:5487-5496.

Kielland, C., E. Skjerve, and A. J. Zanella. 2009b. Attitudes of veterinary students to pain in cattle. Vet. Rec. 165:254-258.

Lascelles, B. D. X., C. A. Capner, and A. E. Waterman-Pearson. 1999. Current British veterinary attitudes to perioperative analgesia for cats and small mammals. Vet. Rec. 145:601-604.

Østeras, O., H. Solbu, A. O. Refsdal, T. Roalkvam, O. Filseth, and A. Minsaas. 2007. Results and evaluation of thirty years of health recordings in the Norwegian dairy cattle population. J. Dairy Sci 90:4483-4497.

Paul, E. S. 2000. Empathy with animals and with humans: Are they linked? Anthrozoos 13:194-202.

Rousing, T., M. Bonde, and J. T. Sorensen. 2000. Indicators for the assessment of animal welfare in a dairy cattle herd with a cubicle housing system. Pages 37-44 in Improving Health and Welfare in Animal Production. EAAP publication 102. H. J. Blokhuis, E. D. Ekkel, and B. Wechsler, ed. Wageningen Pers, Wageningen, the Netherlands.

Singer, T. 2006. The neuronal basis and ontogeny of empathy and mind reading: Review of literature and implications for future research. Neurosci. Biobehav. Rev. 30:855-863.

Templer, D. I., C. A. Salter, S. Dickey, R. Baldwin, and D. M. Veleber. 1981. The construction of a pet attitude scale. Psychol. Rec 31:343-348.

Waiblinger, S., C. Menke, and G. Coleman. 2002. The relationship between attitudes, personal characteristics and behaviour of stockpeople and subsequent behaviour and production of dairy cows. Appl. Anim. Behav. Sci. 79:195-219. 